\title{
Excursions
}

Volume 9, Issue 1 (December 2019) Fake

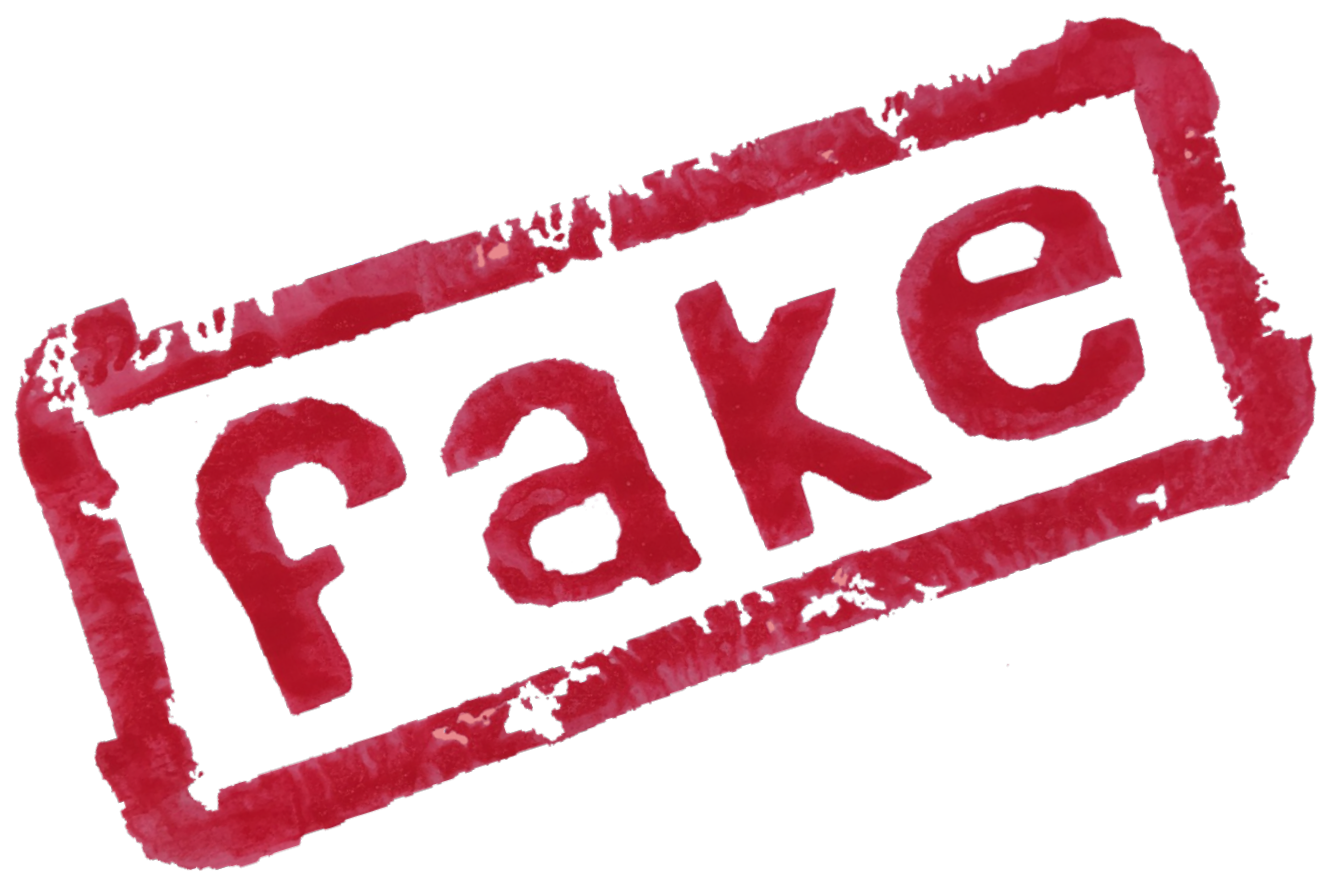

Nicholas Orlando, Deconstructing an Evil Fakeness: Digital Media and Truth in Dan Gilroy's Nightcrawler

Excursions, vol. 9, no. 1 (2019)

https://excursions-journal.sussex.ac.uk/ 
Nicholas Orlando

Hillsborough Community College

\section{Deconstructing an Evil Fakeness: Digital Media and Truth in Dan Gilroy's Nightcrawler}

'He's the worst possible by-product of the American dream, raised on a vocabulary of pure business-speak, and lacking in a single human quality except cunning, drive, and oneupmanship'.

- Tim Robey, The Telegraph

'Do you know what F.E.A.R. stands for? ... False Evidence Appearing Real'. - Lou Bloom, Nightcrawler

In his review of Dan Gilroy's Nightcrawler (2014), The Telegraph's Tim Robey diagnoses the consequences of the uncaring world fostered by contemporary neoliberalism: one is offered no alternative to the dehumanising drive encouraged by a system in which the market, however amorphous, freely regulates all facets of life. In this, Robey implies a precarious dualism in which Lou Bloom (Jake Gyllenhaal), 
the film's loosely-presumed protagonist, exists. Bloom, once marginalised by a neoliberal economic system devoid of care and rife with narcissism, embraces this same discard of ethics in favor of exploitational, sensational, and fake journalism. In doing so, Lou's immersion into the American gig economy reveals the networks of falsehood upon which this system hinges, and simultaneously lays bare the viewer's voyeuristic desires to know the world from a distance. Nightcrawler, from my reading, mobilises an evil view of digital media technologies, most notably the digital camera. In its tangled aesthetics, Nightcrawler critiques an amputative, voyeuristic view of digital media which links fakeness and distance with virtue and violence through Lou. Yet, through Gilroy, it also offers a self-reflexive extensive critique of Lou's voyeurism to reveal the medium of journalism, the economic structures that support it, and the challenge to virtuous freedom this fakeness offers. Nightcrawler calls for a reconfiguration of digital media ethics that does not marginalise fakeness, but rather embraces its modes of abstraction and ambiguity. In this way, we can turn toward our contemporary moment of fake news to advocate for care in news media.

The extant scholarship on Nightcrawler, although scarce given its still recent release, places much of its focus on the film's critique of digital capitalism. According to Boyle (2017: 549), Nightcrawler employs an anti-realist aesthetic to '[tell] a neoliberal origin story of sorts, where fabricated news - signifiers divorces from their real world referents - of the infotainment industry prefigures the "fictitious capital" ... created by Wall Street's financial instruments that collapsed the economy and sounded the death knell of neoliberalism's legitimacy'. Boyle's discussion of fakeness as a signifier brings to light the digital's association within conventional media studies with groundless abstraction. In a slightly different reading of the film, Brayton (2017) contends Nightcrawler reveals psychopathic behavior as the catalyst behind one's success in late capitalism. For Brayton, Lou's desire for profit by way of the bloody scenes he captures is symptomatic of a system that flourishes in its unempathetic distance from human suffering. The sale, with its exchange of goods for capital gain, dominates the late capitalist's interests, and these monetary exchanges, like the digital 
media discussed shortly, remain phenomenologically disconnected from the consumer.

In what follows, then, I turn to reposition media not as an intermediary device, but rather as evil actors in systems of mediation that generate ambiguity and uncertainty. Evil media, for Fuller and Goffey (2014: 3), '[facilitate] and [amplify] the creation of troubling, ambiguous social processes, fragile networks of susceptible activity, opaque zones of nonknowledge - the evils of media'. By maintaining an active role in determining the social relations of which they are a part, media are not evil in a conventional and supernatural wickedness. Rather, for Fuller and Goffey, media are unconventionally evil because they precipitate the production of instability. Fuller and Goffey share my contention that media are inherently unstable, and though they help to forge new social relations in their indeterminacy, they simultaneously perturb the extant social reality. By considering media as objects, they state, 'mediation entails the process of becoming activated, whether one consciously takes on the role of spectator or not' (2014: 2). Further, Fuller and Goffey argue for an 'ethico-aesthetic sensibility' that realises how these objects are made mutable within power structures. For my purposes, the evils of Nightcrawler emerge from the deceit born by its digital, abstract, and thus purportedly fake mediating forms, both within and without its diegesis. Media, in their demand for our spectatorship, activate us as onlookers, inciting modes of looking marked by ambiguity and undecidability. In this construction, consistent with Fuller and Goffey, media are evil in their indeterminacy, an evilness that, I contend, ought to be reclaimed in order to challenge the determinism imposed upon them by the procedures of contemporary mass media.

Whereas Fuller and Goffey forgo questions of spectatorship, Nightcrawler, I argue, reclaims spectatorship as a site for challenge prevailing power structures of news-making. For Marshall McLuhan (1964: 2), all media are extensions of our 'sense lives'; they actively '[shape] and [control] the scale and form of human association and action'. Although Fuller and Goffey give credit to McLuhan and his maxim 'the medium is the message' for influencing their conception of media evilness, they leave behind McLuhan's conception of amputation and extension. An amputative view of 
media removes one's responsibility from the effects they have on the world, whereas an extensive view maintains that sense of responsibility and thinks of media as extensions of the human senses. Nightcrawler critiques this amputative view of digital media as a mode of mediation that allows for the detachment of one's self from material facts and, more generally, the world. If we recognise that all media are extensions of ourselves, we may also recognize our own relationality to the subjects cinematic and televisual media capture. In doing so, media are not merely political instruments of misdirection. Rather, they activate ambiguous and intersubjective connections with others that provide moments of anxious openness otherwise hindered by neoliberal logics self-interest.

Released in 2014, Nightcrawler clearly precedes the Trump Administration's claims of 'fake news', yet it sheds light on a different facet of neoliberal violence from which such claims redirect our attention. In Gilroy's film, Lou Bloom is introduced to us as an unemployed thief who steals industrial materials from private properties and sells them to construction contractors. Unnervingly thin in his physique as he prowls the streets of Los Angeles in an aging automobile, Lou soon discovers a pair of stringers, or nightcrawlers, recording the death and carnage of the city and selling the footage to local television news stations. Inspired, Lou enters this line of freelance work, purchasing some basic equipment from a pawn shop, namely a digital camera and a police scanner. For Lou, in gathering the footage for KWLA, the diegetic news station that forms a working agreement with him, he contributes to the construction of daily 'fake news', or narrativized images of the city's dead, dying, and wounded.

This violence is the foundation on which the Trump's Administration delineations of mass media are built; however, it is often repressed by the immediate implications of Trump's use of the phrase. For Trump, media outlets that actively criticise him or his administration are fake, and his public proclamations of 'fake news' serve as attempts to delegitimise certain news sources, like CNN and The New York Times, or news discourse, such as White House dysfunction, the Trump-Russia Dossier, and his administration's plans to repeal and replace the Affordable Care Act. Trump's deployment of these claims has not escaped critical academic attention. 
According to Farkas and Schou (2018), the phrase 'fake news' acts as a floating signifier within hegemonic struggles for conceptions of truth. As Farkas and Schou (2018: 308) argue, the phrase is meant as a frontal attack on traditional core values of journalistic practice, such as critical investigations of those holding power'. Trump's perversions of the epistemological certainty promised by news media remind us of television news' struggles with balancing spectacle and information before 2016.

If 'fake news', as used by Trump, signifies a failing mass media in its struggle for hegemonic truths, Nightcrawler's 'fake news' signifies the neoliberal violence that links fakeness with the digital and the desired production of fear made manifest by this relationship. KWLA's Nina Romina (Rene Russo), after purchasing her first collection of footage from Lou, describes perfectly the object the film's 'fake news' signifies. She states, 'We find our viewers are more interested in urban crime creeping into the suburbs. What that means, is a victim, or victims, and white, preferably welloff, injured at the hands of the poor or a minority' (Gilroy, 2014). She goes on to say footage of automotive accidents are also acceptable, so long as the content is 'graphic'. KWLA's sensational narrative, that of the white, private suburbs' suffering under a fake threat of urbanity, characterized by Nina as non-white and disorderly, is 'fake news'. Yet, Trump's use of the term exclusively in the political realm actively ignores the very real implications of the media's violence. Nightcrawler, therefor, reminds us of the fear associated with the digital, and, in some suggestive shots throughout the film, looks to and at us for a new ethics of care in our aesthetics.

Nightcrawler substantiates the relationship between the digital and the fake through its diegetic depiction of media voyeurism. Many of the technologies on which Lou relies are digital, including his cameras, police scanner, and computer. Such devices, for some film and media scholars, always remain at a distance from reality, rendering their abilities to convey realism impossible. According to Prince (2004), digital video's default wide-angle format, sharp definition, and near-perfect crispness deaden the potential for realism that remains unique to analog film. Digital media, in this view, struggle to hide their inauthenticity, or their fakeness. Furthermore, Prince 
asserts, because the digital operates by wide-angle image capture and deep focus, digital media thereby deviate from the ethical significance of those same aesthetic choices as applied to the analog. Not only, then, is the digital fake, but it is also devoid of ethical expression and thus conventionally evil, a vision of evil for which I do not argue. Lou engenders Prince's codelike sharpness of the digital and the evil sense of remove it permits. In one particular dissolve near the film's start, a close-up shot of Lou's face briefly merges with a close-up shot of his just off-center police scanner and computer screen [see Figure 1]. The brief superimpositions of Bloom merging with police scanner, human with technology, and Prince's assertion of digital as fake suggest Lou's inhuman and fake digitality fuel neoliberal self-interest, violence, and public fear.

One need not look too far back into television news history to locate the industry's indebtedness to a neoliberal ethos of self-interest and market expansion. News coverage has, as of late, become more about cutting costs and garnering a large viewership rather than promoting national and international awareness. As Robert McChesney (2003) points out, the budget-cutting practices imposed upon contemporary journalism under neoliberalism, and the resulting reliance on alternate modes of funding from advertising, renders the industry more susceptible to corporate interest. Contemporary mass media outlets refocus their resources toward decreasing labor costs, often relying on contract workers who are paid by project rather than by regular salary. Contract workers occupy an intermediary position within the neoliberal labor paradigm, which ultimately enables corporations to disavow ethical responsibility for the financial security of contracted employees and maximize their flows of revenue. Furthermore, because they are beholden to the wishes of advertisers, corporate media often sensationalise their news content, using entertainment value rather than informational value to drive advertising revenue gained from public viewership.

In addition to the reorganisation of news media labor under neoliberalism, which paves the way for unethical reporting and uncaring narratives, Nightcrawler also suggests the problems with television news do not solely rest on the back of the 
media industry. Rather, the film is critical of the voyeurism of public viewership. Writing for The Conversation, Lauren Rosewarne (2013) states the success of news stories about terrorism and shootings relies partly on the viewer's consumption of them. Because television news personalises a tragedy by inviting discussants to provide eye witness testimony of an event, the discussion maintains a relevance to the general public. In this way, as Rosewarne suggests, television news solidifies a tragedy's position within domestic spaces and encourages a morbid voyeurism among viewers. Although she sees this move by mass media as an object of disgust and perversity, she leaves her readers in wonder with her final sentiment. Despite the reality conveyed by emotional and physical wounds inflicted upon bystanders, mass media merely present to audiences an opportunity for sadism rather than information. Rosewarne (2013) concludes, 'That CNN is doing it, however, somehow makes it seem less perverse', thus implying CNN's supposed reliability as a resource for factual information mutes the voyeuristic viewership its coverage of tragedy encourages.

Taken together, McChesney's and Rosewarne's arguments of the neoliberal news industry and public viewership put into sharp relief Nightcrawler's critique of this industry's perpetuation digital media voyeurism, crisis, and precarity. McChesney and Rosewarne reveal a contract worker's livelihood as always precarious, in crisis, teetering on accident, and predicated on the failure of neoliberalism to supply secure employment. In Nightcrawler, these are the very themes Lou is encouraged to shoot in order to perpetuate KWLA's ethos of fear. Victims of traffic accidents and house shootings are not safe from Lou's gaze or KWLA's desire. As Nina explains to Lou after his first sale of footage to the station, it is best to 'think of our newscast as a screaming woman running down the street with her throat cut' (Gilroy, 2014). Although hyperbolic, Nina's comments provide the news' sensationalism with a bodily force whose screams ought not be ignored and spread anxiety throughout the diegetic Los Angeles. Such a force, like the contract worker's livelihood, is always precarious, in crisis, and teetering on accident. And, because neoliberal news relies on immaterial, fake labor relations between employer and worker that are always in crisis and 
teetering on accident, digital media is often conflated with and used to emphasise these anxieties. In this way, digital media are active agents of amputative voyeurism that perpetuate the labor relations, in which they are intertwined. However, I argue this need not be the case. Positioning neoliberal contract labor and neoliberal aesthetics, demonstrated by Nightcrawler's character and form respectively, as institutions with mirroring logics opens a space for reconsideration. In this space, one finds an entangling of aesthetics, which presents a crisis of representation for the spectator.

By plugging into the digital processes of the contemporary news industry, Lou adopts an amputative, voyeuristic eye encouraged by the digital camera and the news industry. For McLuhan, media extend our bodily senses further into the world; however, when one ignores the medium and pays attention to content, he or she severs, or amputates, the connection between self and media. Not only does Lou assume this narcissism, but he also leverages the unreciprocated look of voyeurism as a means for power. Nearly a third of the way through the film, Lou and his partner Rick arrive at the scene of a car crash. To capture the wreckage, Lou runs to record the damage from a higher vantage point. Frustrated by a lack of visibility, he rearranges the mise-en-scene, dragging the dead body into better lighting and retaking his vantage point to continue his amputative voyeurism. This time, the film captures him in a medium shot, as he raises his camera off-screen, and severing his hands by the film's frame [see Figure 2]. The car crash victim cannot look back, thereby granting Lou voyeuristic amputative power in his look through digital media. Though he was once left powerless in a neoliberal economic system, Lou now embodies its logics of self-interest and exceptionalism.

Lou's lack of care for his subjects, and the lack of reciprocity for Lou's look, speaks to the issue of ethical television journalism. Film and media theorist Vivian Sobchack (2004: 254), in her discussion of filming death in the documentary mode, identifies the 'professional gaze' as a mode of looking that requires journalists to evaluate their own ethical values to determine when or if they should intervene. According to Sobchack (2004: 255), '[T]he professional gaze is marked by ethical 
ambiguity, by technical and machinelike competence in the face of an event that seems to call for further and more human response'. Lou Bloom had more than one chance to intervene and provide support, such as calling for help when he films a wealthy victim of a shooting suffering and groaning in pain. Bloom lacks empathy for human beings. If anything, Bloom enjoys looking at these victims. His footage provides a socio-sexual pleasure for him, and he even monitors his progress by watching the broadcast of his footage the morning it airs on television.

News, in this configuration, as well the reality it purports to communicate, become more about the consistency of narrative, the foisting of power, and the eliciting of viewer emotions rather than serving a larger democratic purpose as an informational service. Lou's efforts, then, are conventionally evil, because they capitalize on the viewer's voyeuristic desire to know their surroundings yet see it from a distance. However, if what is digital and fake is evil, and this evilness delegitimizes the validity of digital/fake content, then one must turn toward medium for reconciliation. As Fuller and Goffey (2018: 5) argue, all media are evil precisely because they create 'a troubling opacity and thickness in the relations of which they are a part, with an active capacity of their own to shape or manipulate the things or people with which they come into contact'. A medium's materiality does not determine its truthful or false relationship with reality, as Prince's contention of digital video does. Instead, it is our indeterminate, affective, and essentially bodily relationship with media that determines its validity. That is, media as extensions of our bodily senses, emphasize an opaque and thick relationality with a mediated subject that activates ethics through ambiguity.

Returning to Nightcrawler, when one looks to film form, one sees the film's entangled aesthetics, since it, too, relies on digital cinematography and risks the same amputative voyeurism wielded by Lou. For most of the film's nighttime scenes, Gilroy and cinematographer Robert Elswitt choose to shoot on digital with the Arri Alexa. Digital cameras, according to Elswitt (Desowitz, 2014) are particularly suited for capturing dimly lit environments, and the Arri Alexa even adds a 'dreamy glow' to its footage. In this digital glow, Gilroy himself captures the death and carnage of Los 
Angeles that forms the content of the morning news. This dreaminess is best demonstrated by the film's opening sequence, during which bright electric guitars and crystalline long shots of the LA cityscape seductively lure the viewer into an uncanny world, at once promising safety while withholding its threat. By contrast, the film's daytime scenes are shot on analog, thus grounding these scenes in conventional analog realism by way of its grain. The digital's promise to 'see into the distance', as Elswit (2014) states, also conceals its apparent threat to realism's stability. The digital's dream, then, is a threat cloaked in seductive, seemingly unknowable darkness, ultimately posing the dreamy digital as an imminent threat to the authentic analog.

In his deployment of Steadicam, Gilroy establishes an almost-but not quite relationship between the viewer and Bloom. This enables us, according to film and media scholar Amy Rust, to oscillate between identification with viewer and an extrafilmic body. For Rust (2016: 154), the Steadicam establishes two-way almost-but not quite relationship by combining the first and third person perspectives. Discussing the emergence and use of Steadicam in the 1970s, she argues this device forms a nearidentification between spectator and character and spectator and camera, and 'underscores and undermines the stability and freedom for which it is widely touted'. Instead, in its instability, it draws together freedom and responsibility to supply an ecological ethic, as she terms it; that is, by immersing spectators into other worlds, and, I suggest, especially those uncanny such as Nightcrawler's diegesis, the device demands care for its subjects. Rust's ecological ethic is similar to evil media's ethicoaesthetic sensibility proposed by Fuller and Goffey. If evil media make room for ambiguity in otherwise determinate conceptions of mediation, then, I contend, they can do the same for the representation offered by digital cinema and television news alike. I suggest evil digital media, although easily manipulated in structures of power such as the news industry by way of the ambiguities they introduce, can also demand care for the subjects they mediate.

Turning back to Nightcrawler and its car crash scene, Gilroy juxtaposes the amputative-voyeuristic hand-held camera with the care-inducing Steadicam. In 
Nightcrawler's car crash scene, the Steadicam operator moves with Lou and makes subtle gestures to move away, though it struggles to do so completely [see Figure 3]. The Steadicam's attempts to pull away from Lou, to fulfill its promise for viewercamera identification as proposed by Rust, is disrupted and often disallowed by the film's adherence to conventional editing. This moment reveals Nightcrawler's cinematographic ethical ambivalence: The film at once yearns to distance itself from Lou through its cinematography and also desires the voyeuristic fakeness the digital supposedly promises. Elswitt's digital dreamy glow implies Nightcrawler's world is a desired dream and a grotesque nightmare, lulling the viewer in its affective ebbs and flows. Gilroy, then, cannot fully return his critique of Lou to his own embrace of the digital because his film reveals that both digital cinema and digital broadcast news rely on this sensational, fake dream. Still, this does not further delegitimize the digital's potential to elicit ethical care. In fact, the uncertainty provided by Nightcrawler's entangled aesthetics provides us a moment of critical reflection.

We have reached a moment, it seems, when our modes of representation are so homogenous it becomes impossible to disentangle fact from fiction. Nightcrawler, then, leaves us in unease and uncertainty, and therefor adds to our anxiety of the digital and risks abetting the self-interested logics of neoliberal media. However, it is in this anxiety, this undecidability, and this evilness, that we find a sense of the real in digital mediation in our post-truth era. The real, rather than being a construction that promises material certainty, may deceive us in our own looks outward. Toward Nightcrawler's end, we see Lou and Nina negotiating their final sale of the film, each facing the other in profile in a close-up shot. Their sexually euphemistic language finally puts the film's preoccupations with voyeurism in full thrust. Yet, in the space between, Rick stares at us as his life drifts away [see Figure 4], thus locking the audience into a tension. The images Lou and Nina exploit look back at us, a look that contrasts Lou's evil stare through KWLA's television monitors in its demand for our attention, begging for empathy [see Figure 5]. It is in these looks from Rick and Lou, one pleading while the other warning, that lay Gilroy's call for a new 'ethico-aesthetic sensibility' (Fuller and Goffey, 2014) in our modes of representation. We must choose 
between the seduction of an amputative-voyeurism that perpetuates neoliberal falsehoods and a call for a new ecological ethic in the digital, to borrow Rust's term. Advocating for the latter, we find that what is fake, digital, and evil might help us to pull away from the dizzying sensations of news, and instead push toward a better, careful journalism. 


\section{Figures}

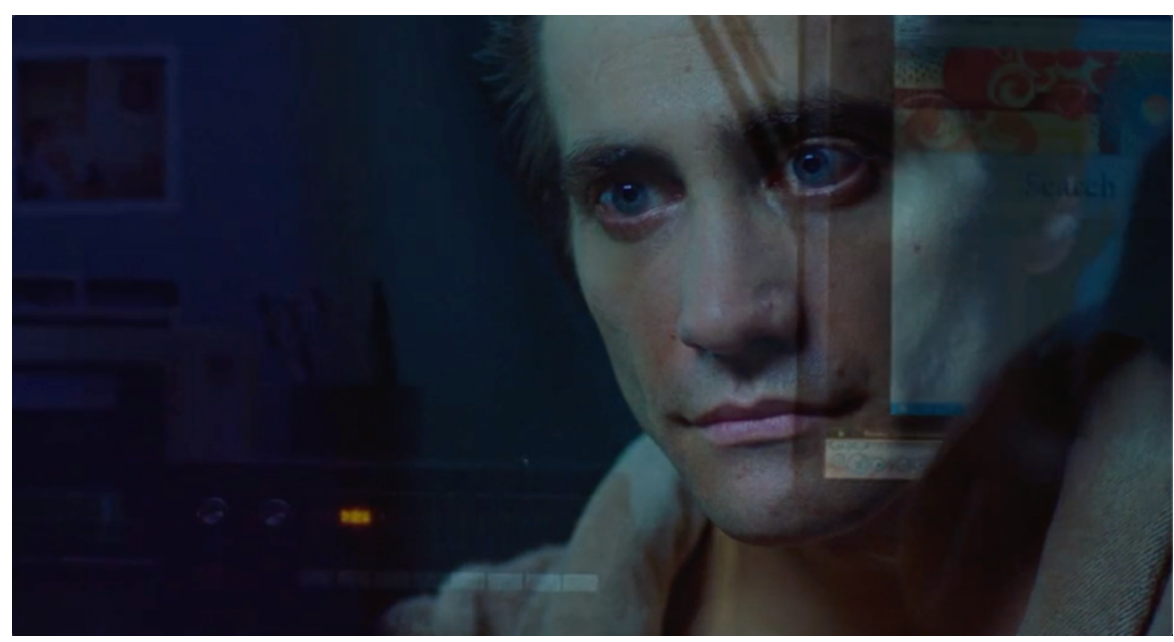

Figure 1: Lou archiving his first video recording onto his computer, 00:22:44

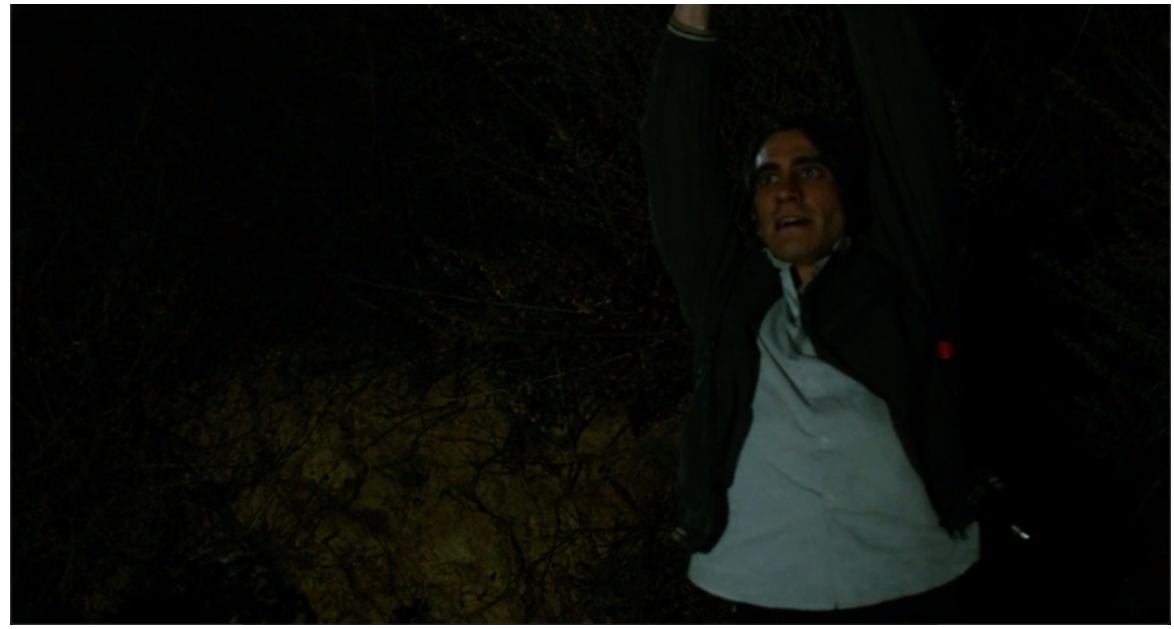

Figure 3: Lou lifting his camera to capture his crime scene re-arranged, 00:41:52

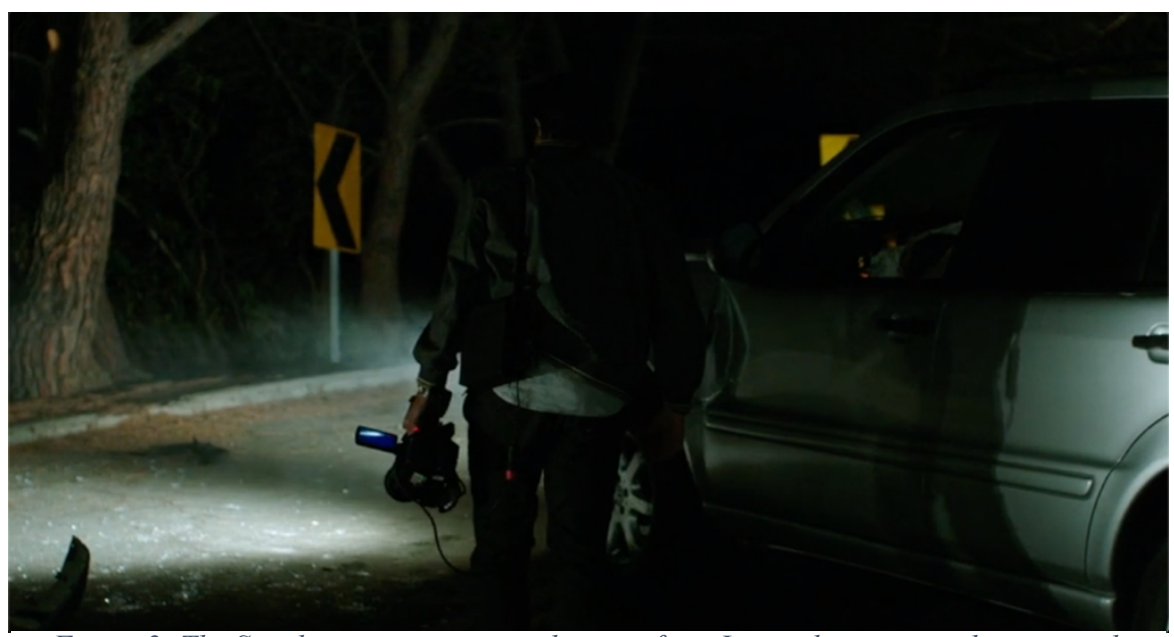

Figure 2: The Steadicam operator stands apart from Lou as he assesses the car crash scene, 00:40:50 


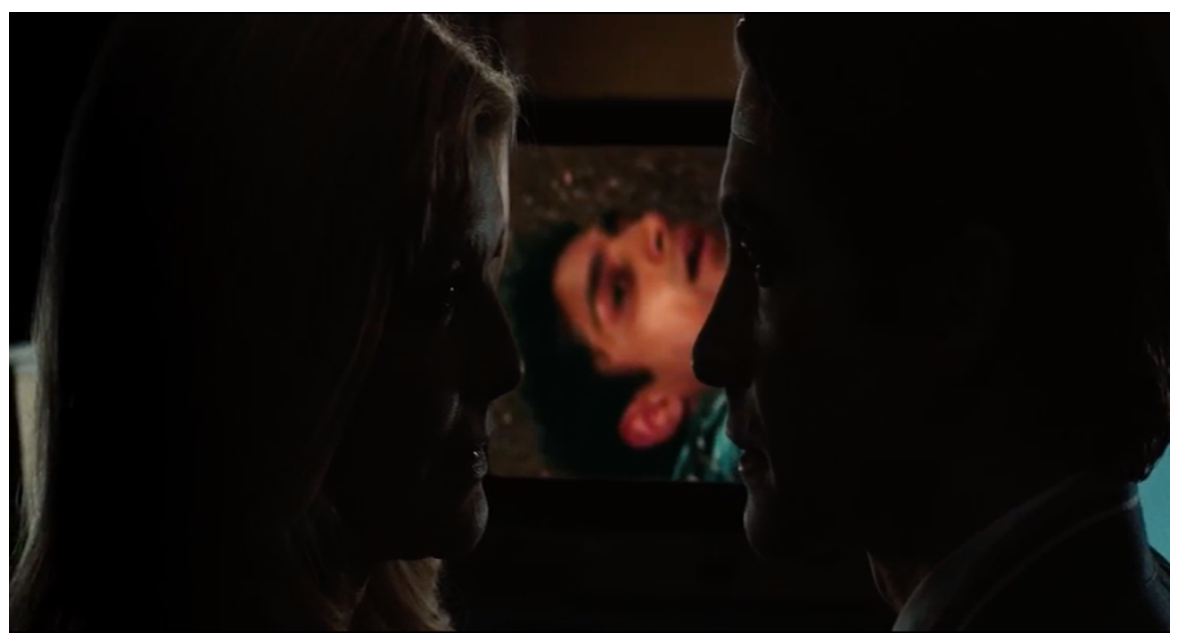

Figure 4: Rick stares at the viewer through a KWLA camera monitor, 01:47:01

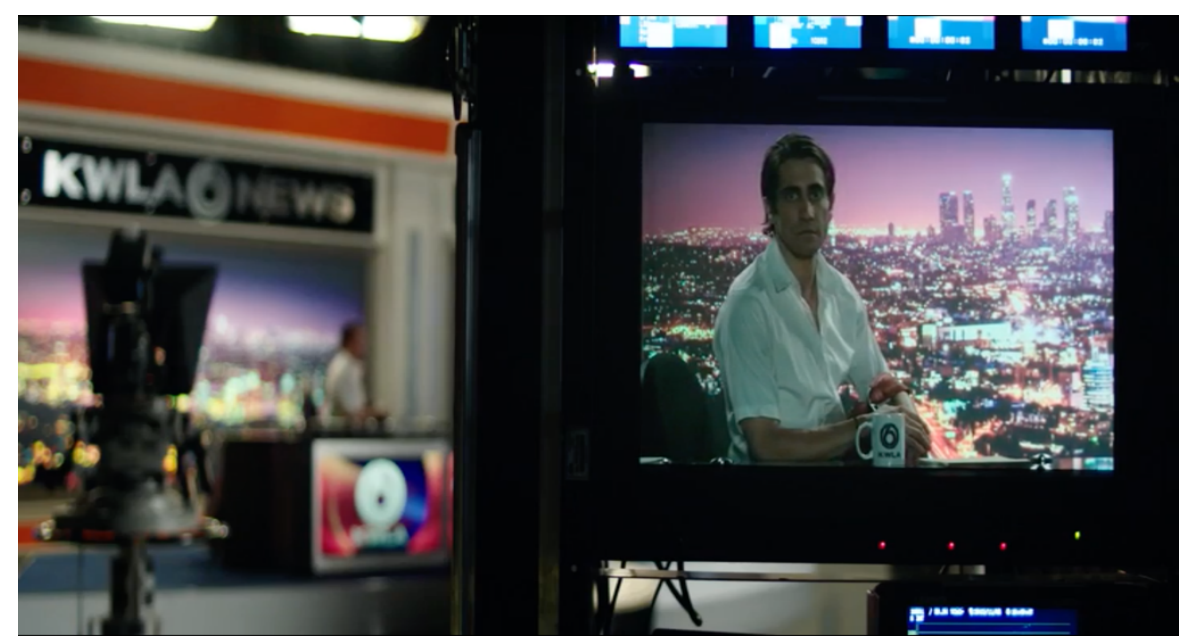

Figure 5: Lou stares at the viewer through a KWLA camera monitor, 00:36:46 


\section{Bibliography}

Boyle, K. (2017) 'Three ways of looking at a neoliberalist: mobile global traffic in Cosmpolis and Nightcrawler', Quarterly Review of Film and Video, 34(6), p535559

Brayton, S. (2017) 'The "madness" of market logic: mental illness and late capitalism in The Double and Nightcrawler', Communication and Critical/Cultural Studies, 14(1), p66-82

Desowitz, B. (2014) 'How “Inherent Vice” \& “Nightcrawler” DP Robert Elswit captures the pulse of LA' IndieWire, 31 October [online]. Available at:

http://www.indiewire.com/2014/10/how-inherent-vice-nightcrawler-dp-robertelswit-captures-the-pulse-of-la-190358/

Farkas, J. and Schou, J. (2018) 'Fake news as a floating signifier: hegemony, antagonism, and the politics of falsehood', Journal of the European Institute for Communication and Culture, 25(3), p298-314

Fuller, M. and Goffey, A. (2014) Evil media. Cambridge: MIT Press

Lombos, D. and Leverstein, S. (2014) 'The shell game of contingent employment', Political Research Associates [online]. Available at:

http://www.politicalresearch.org/2014/o9/01/theshell-game-of-contingent-employment/\#sthash.yVJe4knU.H5KHTN8F.dpbs McChesney, Robert W. (2003) 'The problem of journalism: a political economic contribution to an explanation of the crisis in contemporary US journalism.' Journalism Studies, 4(3), 229-329

McLuhan, M. (1964) Understanding Media: The Extensions of Man. New York: McGraw - Hill

McNair, B. (2018) Fake news: falsehood, fabrication, and fantasy in journalism. London: New York: Routledge

Nightcrawler (2014) Directed by Dan Gilroy [Film]. Los Angeles: Universal Studios Home Entertainment, 2014

Prince, S. (2004) 'The emergence of filmic artifacts: cinema and cinematography in the digital era.' Film Quarterly, 57(3), p24-33

Robey, T. (2014) 'Nightcrawler, review: "jet-black laughs”' The Telegraph, 30 October [online]. Available at: 
http://www.telegraph.co.uk/culture/film/filmreviews/11077789/Nightcrawlerreview-jet-black-laughs.html

Rosewarne, L. (2013) 'Navy yard shootings: what does an "immediate” media response actually provide?' The Conversation [online]. Available at:

http://theconversation.com/navy-yard-shootings-what-does-an-immediatemedia-response-actually-provide-18274

Rust, A. (2016) “'Going the distance”: Steadicam's ecological aesthetic' in Starosielski, N. and Walker, J. Sustainable Media: Critical Approaches to Media and Environment. New York: Routledge, p146 - 159 Sobchack, V. (2004) 'Inscribing ethical space: ten propositions on death, representation, and documentary', Carnal thoughts: embodiment and moving image culture, Berkeley and London: University of California Press, p226-257 Strauss, N. (2016) 'The age of fear', The Rolling Stone, 20 October, pp.42-56 